\title{
EL PAPEL DE LA IGLESIA DE CENTROAMERICA EN LA GUERRA CONTRA WILLIAM WALKER (1856-1860)
}

\author{
POR \\ ALEJANDRO S. SAGASTUME FAJARDO \\ Universidad Nacional Autónoma de Honduras (Tegucigalpa)
}

\section{El PASADO INMEDiato}

Es un hecho que Centro América, es decir, la antigua Audiencia de Guatemala, llegó dividida al proceso de su independencia de España en 1821. Dos grupos sociales e ideológicamente definidos se perfilaban y se enfrentaban en la búsqueda del poder republicano. La idea de formar una federación era, sin duda, un triunfo liberal, pues la Constitución Federal de 1824 estaba inspirada en la de Cádiz y en la Carta Magna de los Estados Unidos. Esto chocaba con los intereses y la intransigencia de los conservadores y sacó a flote las contradicciones entre ambos grupos. El reciente pasado colonial legaba «una pesada herencia de aislamiento, falta de integración regional, agudas rivalidades y localismos» (1). El Reino de Guatemala se mantuvo unido, en la etapa colonial, sólo en lo administrativo y en el hecho de compartir una misma religión, lengua y determinadas costumbres.

Las medidas tomadas por los liberales encontraron oposición y se desató la guerra civil. Desde 1826 hasta 1829 cruentas batallas ensangrentaron el área. El triunfo liberal de Francisco Morazán agudizó el antagonismo político, al atacar éste a la Iglesia, sector social que mantenía intactos sus privilegios ancestrales. El nuevo gobierno abolió los diezmos, introdujo el matrimonio civil, dio libertad de cultos y llegó a expulsar a las órdenes religiosas del istmo (2). Las medidas económicas se orientaron

Sigla UTII.IZADA:

AMAE: Archivo del Mo de Asuntos Exteriores, Madrid.

(1) Ciro Cardoso y Hector Pierliz. Bricinoli, Centroamérica y la Ecomomia ()cidental (1.524-19.3.3) San Jusé, EDUCA, 1976.

(2) Luis Mariñas OThro, Honduras. Tegucigalpa, Ed. UNAH, 1987. Cap. XVIII. 
hacia el comercio libre con el mundo (sobre todo con Inglaterra), y se creó una legislación que protegía e incentivaba la inmigración y la industria.

Estas medidas fracasaron y la Federación se rompe definitivamente en 1839. Las dificultades para crear un estado nacional a nivel centroamericano quedaron evidenciadas ante la falta de una clase social que construyera un poder fuerte, estable y hegemónico. Por otro lado, las estructuras de poder colonial se habían heredado intactas, y se padecía de un localismo acendrado, aislamiento y rencillas provinciales, además de las deficiencias administrativas que sirvieran para dar unidad a la región. El conservadurismo guatemalteco, dominante en el antiguo Reino "condenaba el progresismo defendido por los otros Estados, obligando a un estancamiento en las antiguas formas coloniales" (3).

La muerte de Morazán, en septiembre de 1842, termina con el lider de más valía para intentar de nuevo la unión de Centro América; a partir de este momento cada país tratará de dirigir su propia historia nacional y buscará distintas fórmulas para lograr su desarrollo.

\section{NicARAGUA: LOS HECHOS DE LA GUERRA}

La ganadería es el elemento económico que domina y caracteriza la historia nicaragüense en el siglo XIX. La sociedad tradicional se manifestaba en el minifundio, un mercado escaso y regional, un bajo nivel técnico y un limitado modernismo en el aparato estatal. Tierra rica y pródiga, Nicaragua vivía entonces una etapa de estancamiento y una pobreza extendida, debido a la inestabilidad política, manifiesta en constantes revueltas armadas, que los sectores de poder, en pugna constante, habían producido. Los viajeros extranjeros que cruzaban el territorio de Nicaragua se percataban de la riqueza aún no explotada del país. Un viajero norteamericano que llegó a Nicaragua en 1856 expuso, entonces, esta opinión:

Las capacidades de Nicaragua, y en especial de la parte Sur del país, son todavía desconocidas y hasta el presente no parece haber estímulos para el desarrollo de sus recursos. Se necesita de una actividad grande a fin de hacer realidad las ventajas

(3) Mario Argueta y Edgardo Quiñonez, Historia de Honduras. Tegucigalpa, Escuela Superior "Francisco Morazán", 1978. 
que ofrece el pais, una protección para el trabajo ! la garantia de un gobierno estable y capaz (4).

Ese gobierno estable y capaz era el que habia hecho falta. Liberales y conservadores se habian enfrascado en luchas políticas y habían arruinado la nación. No se descarta en estas luchas, las ingerencias de los gobiernos de los otros países del área, que apoyaban al gobernante de turno según fuera su filiación partidista. Rafael Carrera, en Guatemala, en más de una vez intervino en los asuntos internos de los otros países, pretendiendo expandir su poder, lo que motivó en más de una ocasión guerras entre naciones vecinas.

Los sueños, proyectos y planes, muy antiguos por cierto, de unir los océanos Atlántico y Pacífico, a través de Nicaragua, por medio de un canal marítimo, toman mayor relevancia a partir de la segunda mitad del siglo XIX. Los intereses europeos, especialmente los de los ingleses, por expandir el comercio mundial y tener áreas de influencia política a su favor, chocarán de lleno con los intereses de los Estados Unidos, quienes ya andaban buscando provecho económico y político en Centroamerica. Las disputas se resolverán al firmarse el Tratado Clayton-Bulwer en 1850, que significó "la decadencia de los intereses británicos en Centroamérica y el Caribe, y el ascenso de la influencia norteamericana en el área» (5).

En las elecciones realizadas en Nicaragua en 1852, de una contienda entre veintiséis candidatos, resultó electo Don Fruto Chamorro, representante del Partido Legitimista o conservador; se le acusó de haber hecho trampa y fraude en el proceso electoral, por lo que su gobierno comenzó ya marcado por el estigma de la corrupción. Por otro lado, en 1849, Cornelio Vanderbilt, asociado con Joseph L. White y Nathaniel Wolfe, norteamericanos todos, organizaron "The American Atlantic and Pacific Ship Canal Company" con el propósito de construir el famoso canal interoceánico, quedando sus trabajos en los preliminares, solamente. Al no poderlo construir, la compañía se convirtió, en 1851, en la "Compañía Accesoria de Tránsito" (6) dedicada al transporte de carga y de pasajeros de un mar a otro. En el contrato hecho con el gobierno, ésta compañía se comprometía

(4) William V. Wist.s, Exploracione's y Aventuras en Honduras. 1857. San Jusé. EDUCA, 1983. Cap. I, pág. 20.

(5) ARgueta [3].

(6) Miguel A. Át.varizz, Los filibusteros en Nicaragua. Managua, Edit. La Prensa, 1944. Cap. l, pág. 5. 
a respetar las leyes del país y a pagar el $10 \%$ del total de sus utilidades. Cuando Chamorro subió a la presidencia, la compañía se negó a cumplir las contratas aduciendo pérdidas económicas y pretendía que el nuevo gobierno le excusase de pagar lo suyo. Ante la negativa de Chamorro la compañía buscó, entre los sectores contrarios al gobierno, en quien apoyar una insurrección. Además, la administración Chamorro «comenzó con la emisión de varios decretos tiránicos, entre ellos el que suprimió la Corte Suprema y el que le confería el poder dictatorial supremon (7).

Don Francisco Castellón, liberal y al momento ministro de Relaciones Exteriores, se levantó en armas y apoyado por el gobierno de Honduras decretó la revolución, en 1854. Las ciudades de León y Chinandega, de arraigo liberal, apoyaron a Castellón, mientras que el presidente Chamorro se refugió en Granada, antiguo bastión aristócrata y conservador, dejando de nuevo, al descubierto, la ancestral rivalidad entre éstas ciudades. La anarquía y la desesperación llegó a la población, que vio prolongarse la guerra en sangrientas batallas. El 12 de marzo de 1855 muere Chamorro y asume el poder, provisionalmente, el general Estrada, llegando éste a recuperar militarmente todo el país, excepto el departamento Occidental, en donde la política liberal de los seguidores de Castellón lo mantenían como su líder.

\section{William WaLKER ENTRA EN ESCENA}

Necesitando de armas y hombres, Francisco Castellón, apurado ante una posible derrota, firmó un convenio con el norteamericano Byron Cole para que éste reclutara hombres en Estados Unidos para luchar por su causa. A estos mercenarios se les pagaría bien, se les daría la nacionalidad nicaragüense y se les concedería tierras de cultivo como un premio. Así fue cómo «el 4 de mayo último (1855) el pirata Walker, de conocida y triste celebridad en Sonora y en Baja California, salió del puerto de San Francisco, a ciencia y presencia de las autoridades federales del Estado, y a principios de junio siguiente logró desembarcar, con sus secuaces en el Realejo, unos de los puertos principales de la República, en la costa del Pacífico...» (8).

Según parece, la compañía Accesoria de Tránsito había reco-

(7) Wel.Ls, [4]. Cap. XXV, pág. 454.

(8) Carta del encargado de Negocios de España en Nicaragua, Washir.gton, 10 de noviembre de 1855. AMAE, leg. 2.566. 
mendado que fuera Walker el escogido, porque éste tenía experiencias mercenarias en México y apoyaría el proyecto del canal sin pedir cuentas. Walker, ya en Nicaragua, logró concertarse más y más con los de la compañía, quienes upusieron a la disposición de los piratas americanos los vapores que la Compañía tiene en el Lago. Aprovechando el silencio y la oscuridad de una noche, los piratas sorprendieron y ocuparon, atacando por la retaguardia, la ciudad de Granada, residencia del gobierno" (9). El resultado fue el derrocamiento del gobierno y el fusilamiento de algunos lideres conservadores, mientras que Walker se autonombró general, tomando el mando de las fuerzas armadas del país.

Con el poder militar en sus manos, Walker decide gobernar por su cuenta y traiciona a los que lo habian solicitado, y para tal fin se nombrará, en octubre de 1855, a don Patricio Rivas como presidente provisorio, mientras la sombra vigilante de Walker le rodeaba las espaldas. Esto cambiaba el panorama político de la nación y quedaban claros cuales eran los planes del invasor. Mediante decreto del 23 de noviembre de 1855, Walker motivó la llegada de más aventureros al estimular la inmigración extranjera, premiando a los que llegaran con 250 hectáreas de buena tierra por cada adulto, más otras cien si eran familia; además, estos emigrantes no pagarían impuestos ni tasa alguna por llevar bienes inmuebles, siendo acogidos como ciudadanos ejemplares. Igualmente se ordenó que todos los decretos, acuerdos, leyes, etc, fueran escritas en español e inglés y que se confiscaran las propiedades de los contrarios. Asimismo, se editaba un periódico semanal titulado El Nicaragüense que escrito en inglés y español, a dos columnas, informaba de todo lo relacionado al régimen (10).

El desmesurado poder que Walker estaba tomando en Nicaragua alarmó a los restantes gobiernos de Centro América. Costa Rica, que tenía graves contradicciones con su vecino por disputas limitrofes, dio la voz de alerta y su presidente, Juan Rafael Mora, hizo ver a su pueblo del peligro que corrian, ante la posibilidad de que los mercenarios invadieran su país. El 20 de noviembre de 1855 vio luz pública el llamado del presidente:

Costarricenses: una gavilla de advenedizos, escoria de todos los pueblos, condenados por la justicia de la Unión americana, 2.566 .

(9) Carta del Encargado de Negocios de España en Nicaragua. AMAE, leg.

(10) Algunos números sueltos de este periódico se hallan en AMAE, sección Centro América. 
no encontrando va donde hov están con que saciar su voracidad, provectan invadir a Costa Rica para buscar en nuestras esposas e hijas, en nuestras casas y haciendas, goces a sus feroces pasiones, alimento a su desenfrenada codicia.

Yo velo por vosotros, bien convencido de que en el instante de peligro, apenas retumbe el primer cañonazo de alarma, todos, todos os reuniréis en torno mío, bajo nuestro libre pabellón nacional (11).

El 26 de febrero de 1856 Costa Rica declara formalmente la guerra al gobierno de Nicaragua, invitando a los otros países del área a unirse a la lucha. El Congreso costarricense autorizó a Mora para que omnímodamente "por sí, o en unión de las fuerzas aliadas de los demás gobiernos de Centro América, lleve sus armas a la república de Nicaragua para defender a sus habitantes de la ominosa opresión de los filibusteros, y arrojar a estos del suelo de toda la América Central» (12).

Walker, por su parte, procuró atraer más seguidores a su causa, sobre todo a norteamericanos, a quienes prometía riquezas, gloria y la subyugación por la raza blanca de la "raza inferior", como en su momento llegó a definir a los habitantes de Centroamérica. En efecto, en marzo de ese año, el vapor "Carlos Morgan" salió de Nueva Orleans conduciendo 208 hombres armados para unirse a Walker; entre ellos iba Enrique Walker, hermano del filibustero y otros norteamericanos y extranjeros (franceses y algunos españoles).

Las pretensiones de los invasores se vieron pronto con claridad: Walker pretendía anexionar Nicaragua como un estado esclavista más a los estados del sur de la Unión Americana; introducir libertad de cultos y enajenar las tierras. Los que antes habían visto a los norteamericanos como salvadores de la anterior dictadura, se convencieron del peligro que corría su libertad. Patricio Rivas, todavía presidente provisional, tomando nota de la situación, abandonó Granada y se trasladó a León, rompiendo con Walker y declarándolo enemigo y traidor, porque pretendía «arrebatar el poder público por medio de la fuerza... practicar innovaciones políticas y religiosas en Nicaragua... y sobre facultades omnímodas que exijía se le confiriesen, a fin de proveerse de recursos, sin excluir el medio de confiscar y vender a extranjeros las propiedades de los particulares" (13). Al declararle traidor le

(11) Gaceta de Guatemala, 11 de enero de 1856. En AMAE, Leg. 2.566.

(12) Diario El Progreso, Guayaquil, 5 de abril de 1856, AMAE, Leg. 2.566.

(13) Gaceta de Guatemala, 1856, AMAE, Leg. 2.566. 
destituía del grado de jefe del ejército nacional, haciendo un Ilamado a toda la población a levantarse en armas contra Walker. Este contraatacó políticamente anulando todos los decretos y leves emitidas por Rivas y preparando unas elecciones que lo nombraran presidente. En junio de 1856 Walker es nombrado presidente de Nicaragua, con los votos de sus seguidores y de algunos miembros del Partido Conservador, que se habían unido a los extranjeros. En su discurso de toma de posesión dijo:

Los cuatro Estados de Centro América, sin razón y sin justicia, se han dado a la tarea de intervenir en los asuntos domésticos de Nicaragua, conscientes de su propia debilidad y temerosos de que la prosperidad de Nicaragua se realice a expensas de su riqueza, los Estados vecinos estan envidiosamente tratando de interrumpir nuestro progreso por la fuerza de las armas. Los imbéciles gobernantes de esos Estados, también, sintiendo que han fracasado en el cumplimiento de sus deberes hacia los pueblos que gobiernan, temen que sus empobrecidos compatriotas puedan finalmente buscar refugio en quienes han redimido a Nicaragua de la anarquía y la ruina (14).

Ante el peligro de la expansión del régimen defacto de Nicaragua, los demás países centroamericanos, por fin y olvidando las asperezas existentes entre ellos, decidieron actuar. Tropas de El Salvador, Guatemala y Honduras, en un solo ejército, penetraron en territorio nicaragüense. A los ejércitos se unía la colaboración de la población, que contribuía con víveres, medicinas, dinero y arengas patrióticas. Una de las más sangrientas batallas tuvo lugar en Rivas, en abril de 1856, en que Walker resultó derrotado estrepitosamente. Sin embargo, la suerte se iba alejar del bando unionista, al ser atacadas las tropas por un enemigo más feroz: la epidemia del cólera morbus, terrible y contagiosa enfermedad que había aparecido hacia finales de 1855 y que se propagó al año siguiente. Costa Rica fue el país más afectado, tanto que se llegó a temer un triunfo de Walker, porque la enfermedad había diezmado al ejército «tico». Miles de personas murieron, incluidos muchos filibusteros y altos jefes militares de ambos ejércitos. En algunos momentos la enfermedad obligó a los contendientes a paralizar la lucha y dedicar las atenciones a los enfermos. En las labores de curación debemos destacar el

(14) J. Ricardo Dueñas Vansevliken, La Invasión Filibustera de Nicaragla $y$ la Guerra Nacional. San Salvador, Mº de Educación, 1962, pág. 32. 
papel de los religiosos, que afanosamente atendian a los que padecían el mal.

Finalmente, en febrero de 1857, el filibustero Walker es definitivamente derrotado por las tropas aliadas, debiendo huir, vencido y humillado hacia Estados Unidos, su patria natal. Para dejar constancia histórica de su labor se dedicó a escribir una memoria de los acontecimientos y planeando regresar a lo que consideraba su destino manifiesto. En efecto, en mayo de 1858, Nicaragua y Costa Rica denunciaron, ante la comunidad internacional, una amenaza de una nueva invasión de filibusteros estadounidenses, que aunque oficialmente reprobada por el gobierno de los Estados Unidos, se preparaba «bajo la protección del mismo como el único medio de que al fin se pueden valer para posesionarse de Centro América, si ésta rehusa someterse voluntariamente a los Estados Unidos" (15). Ante esto dispusieron su independencia y nacionalidad bajo la protección de Inglaterra, Francia y Cerdeña, suplicándoles defendieran su libertad. Al mismo tiempo acusaban al representante de los Estados Unidos en Nicaragua, Mr. Wheller, de ser el instigador y promotor de nuevos intentos de agresión de los filibusteros.

En diciembre de 1859 William Walker intenta invadir de nuevo a Centro América, pero fracasa, al naufragar los barcos en que se conducía su gente. En septiembre de 1860, otra vez Walker, aduciendo a una supuesta solicitud de los pobladores de las Islas de la Bahía, de quererse independizar de Honduras, llega a Trujillo y se posesiona de este puerto. Hipotecada la aduana de Trujillo por el gobierno hondureño a Inglaterra, en pago de una deuda pública, el «Comandante de la Corbeta de guerra de hélices de su majestad británica 'Ycarus' intimó a Walker la desocupación de Trujillo. Salió éste de allí con unos 80 hombres en dirección al interior por el río Negro. Perseguido por las fuerzas reunidas del país al mando del general Alvarez, y los botes de la 'Ycarus', fueron todos apreendidos y conducidos en la Corbeta a Trujillo, donde Walker y Rudler su segundo han sufrido la última pena, y á los demás se les ha mandado a los Estados Unidos» (16).

Con el fusilamiento de Walker terminaron los intentos de anexión esclavista del territorio nicaragüense. El alto costo humano de la guerra, tanto por las luchas armadas como por la epidemia del cólera, y el enorme gasto económico que significó

(15) Boletin Oficiah, San Salvador, julio 9 de 1858. AMAE, Leg. 2.566.

(16) Carta del Consul de España, San José, 16 de octubre de 1860. AMAE, Legajo 2.566. 
este proceso redujeron las economías de Costa Rica y Nicaragua, que tardaron mucho en recuperarse de las secuelas de tan funesto suceso histórico.

\section{El PAPEL DE LA IGLESIA}

Las situaciones de crisis vividas entre la Iglesia y Estado, a nivel centroamericano, en el proceso de la fracasada república federal fueron superados prontamente al recuperar el clero todos sus derechos y privilegios que se les había quitado. En efecto, las medidas liberales que anteriormente se habían aplicado quedaron sin validez al recuperar la Iglesia sus privilegios, luego que una reacción conservadora se hiciera con el poder en la región. $\mathrm{Si}$ bien como poder socio-político, la Iglesia nunca sería la misma, al ir reduciendo su papel dominante en la sociedad e irlo tomando el Estado. Los conflictos más graves y las rupturas entre ambas instituciones sólo se verán a partir del momento en que las "Reformas liberales" se hacen con el poder en el istmo, esto es, en el último cuarto del siglo XIX.

Cuando se declara el levantamiento militar de Francisco Castejón contra Chamorro, Nicaragua se hallaba en sede vacante y su diócesis era gobernada por el Vicario Capitular Jose Hilario Herdocia, que residía en Granada. El resto de las repúblicas centroamericanas contaban con sus respectivas autoridades eclesiásticas.

A la Iglesia, como guía espiritual y moral de los fieles, le importaban y preocupaban las constantes luchas políticas que enfrentaban a los pueblos, con su lastre de destrucción, muerte y pobreza, sin olvidar los saqueos de casas, locales, templos, conventos e iglesias, que no escapaban a la rapiña de cualquiera de los bandos en contienda. De tal manera que los sacerdotes mismos participarán, de diversas formas en el desarrollo de acontecimientos políticos. Así, cuando la guerra nicaragüense empezaba, el gobierno de El Salvador, recurrió a los buenos oficios del presbítero Manuel Alcaine, para que intercediera entre los contendientes como mediador, para buscar la paz, labor que resultó inútil, como ya vimos.

La nueva fase política que implicó la llegada de los filibusteros nortcamericanos alarmó a los pobladores, sobre todo cuando el triunfo de éstos, con mejores armas y estrategia de guerra, definió el bando ganador. A la voz de alarma y al llamado a la lucha que 
había dado el presidente Mora, de Costa Rica, se unió la voz y el mensaje del obispo de San José, Anselmo Llorente y la Fuente, quien, mediante un edicto, que mandó a hacer público, llamó a los religiosos y fieles de su obispado diciendo:

Encendida la discordia en la vecina República de Nicaragua, excitados los ánimos hasta el frenesí, ciegos de odio y devorados por la ponzoñoza venganza, llamaron una banda de foragidos heces corrompidas de otras naciones. A favor de la dislocación social de aquel desgraciado país, los advenedizos se encontraron bien pronto dueños y señores de él: crecen y no contentos con la presa, estienden sobre nuestro suelo su ávida mirada. Enemigos encarnizados de la religión santa que profesamos ¿qué será de nuestros templos, de nuestros altares y de nuestra ley? ¿cuál la suerte de los ungidos del señor?... Nosotros pelearemos por nuestras vidas y por nuestras leyes: ellos vienen a nosotros con actitud insolente y con orgullo, para destruiros con vuestras mujeres y con vuestros hijos, y para despojarnos: más el Señor los confundirá: por tanto, no los temáis (17).

En su mensaje alertaba al país de los planes esclavistas de Walker y llamaba a la defensa de "nuestra religión, de nuestra patria, de nuestra independencia, nuestras leyes, vidas y propiedades" (18). Sus palabras llevaban el recordatorio de renovar los espíritus y borrar sus pecados, implorando la ayuda divina en la oracion. La lucha contra Walker implicaba, además, una especie de "cruzada religiosa", pues éste ya había anunciado su disposición de dar libertad de cultos en Nicaragua e introducir el protestantismo.

La unión política Rivas-Walker fue vista, por los sectores de la sociedad nicaragüense, de distinta forma. Para los liberales esto no era más que la prolongación de la guerra y el peligro de perder la libertad; para los extranjeros de la Compañía era la oportunidad que esperaban y para los gobiernos de los países vecinos era también un peligro muy cercano. El vicario capitular de Nicaragua, Herdocia, creyó que con la caída de Chamorro llegaba por fin la paz a su nación y por tal razón hizo saber su opinión al nuevo gobierno:

(17) Gaceta de Guatemala, 11 de enero de 1856. AMAE. Leg. 2.566.

(18) Ibidem. 
Señor Jeneral Don Guillermo Walker

León, noviembre 26 de 1855

Apreciado señor.

Hace días que deseaba cumplir con el deber que me demanda la armonía y la amistad, cuyas dos cosas eslabonan las buenas relaciones que deben reinar entre las autoridades y como amigo particularmente; por lo mismo felicito a US. ahora por la victoria habida por los principios libres, que son los que ilustrarán a nuestro pais y le conducirán al emporio de su felicidad: asi me lo prometo de su carácter y filantrópicos sentimientos: felicito a mi patria porque va saldrá de los escombros en que ha sido sumida por el espacio de más de treinta años, no dudando que breve veré desarrollar la ilustración, el comercio y demás artes.

Quiera la divina Providencia le conserve, y mientras tanto reciba US. las muestras del más alto aprecio y adhesión con que me firmo su atento amigo y Capellán q. b. s. m.

Jose Hilario Herdocia (19)

De inmediato contestó Walker, sintiéndose halagado que la primera autoridad eclesiástica reconociera su labor, agradeciendo el gesto del prelado y pidiéndole sus oraciones en favor de su empresa, convencido que sus acciones eran "deducciones legítimas de las doctrinas inmaculadas del Redentor" (20). Confiaba en que con el auxilio de la Iglesia el nuevo gobierno terminaría siendo aceptado por todo el pueblo, debido a la influencia que los sacerdotes tenían en las opiniones de sus fieles. Seguramente, aunque deben buscarse otras causales, fueron estas razones las que determinaron que Walker nombrara como representante de su gobierno, ante el de los Estados Unidos, al presbítero Agustín Vigil, un buen teólogo, orador y político, que fue reconocido como embajador. Esto generó la inmediata protesta de los países centroamericanos, quienes veían en tal aceptación un aval político para los planes expansionistas de Walker, y una clara intención de poner en práctica la doctrina Monroe. Un estudio de más prof undidad ayudaría a comprender mejor el papel desempeñado por el Padre Vigil en este proceso.

Las acciones militares provocadas por la guerra causaron grandes daños materiales en las principales ciudades nicaragüenses. La ciudad de Rivas, considerada bastión del ejército unionista,

(19) El Nicaragïens.e', I de diciembre de 185. AMAE, Leg. 2.566.

(20) Ibidem. 
fue arrasada varias veces sufriendo la destrucción de muchos de sus edificios. Los intentos por apropiarse de la ciudad, por uno u otro bando, destrozaron las construcciones, incluidos los templos católicos, que en más de una ocasión fueron utilizados como fuertes militares o puntos estratégicos para la lucha. Tal es el caso del asalto a la parroquia de la ciudad, ejecutado por las tropas de Walker en la primera gran batalla que lo derrotó, el 11 de abril de 1856, en que utilizando la iglesia como cuartel, la profanaron. Dicho suceso quedó registrado, históricamente, en la siguiente carta que fue dirigida al obispo de San José en Costa Rica:

Informamos al mismo tiempo a US. Ilustrísima que la fuerza de Walker, al atacarnos, se apoderó de la iglesia parroquial de esta ciudad, cometiendo los mayores excesos, sin acatar que aquella era la casa del Dios verdadero.-Por dicha el Señor Cura había consumido con anticipación el Santísimo Sacramento.-El enemigo saqueó los vasos sagrados y robó cuanto pudo de alhajas y vestiduras-Profanó las imágenes y ornamentos, arrojándolos al suelo, llevando su impiedad al estremo de servirse de las primeras para trancar las puertas y parapetarse con lo cual se mutilaron y rompieron varias. Llevaron la impiedad hasta el estremo de introducir mujeres en el templo. Los manípulos y estolas fueron profanados sirviendoles de venda a sus heridos (21).

La elección de Walker como presidente preocupó a todos. El tifus y el cólera habían hecho estragos entre las tropas aliadas y se temía una desmoralización ante la magnitud del problema. Es a partir de este momento, mediados de 1856, en que la unidad de todos los sectores sociales centroamericanos, se hará granítica, uniendo sus voluntades y sus fuerzas. La emisión de la ley de esclavitud, promulgada por Walker, en septiembre de ese año, preocupó más; se ponía en evidencia las intenciones del norteamericano de anexar una colonia a los estados esclavistas del sur de Estados Unidos, de los cuales esperaba obtener el apoyo, armas y hombres.

La unidad social incluyó también a la Iglesia. El arzobispo de Guatemala y los obispos de Honduras y El Salvador unicron sus voces a las llamadas del de Costa Rica, preocupados por la situación. El 4 de septiembre, don Hipólito Casiano Flores y Castro, entonces obispo de Honduras, dictó una pastoral, conde-

(21) Gacela de El Salvador, mayo 13 de 1856, AMAE, Leg. 2.566. 
nando, sin dudarlo, la invasión y el oportunismo del aventurero, exhortando a los párrocos y sacerdotes de su diócesis, a fin de que «con sus frecuentes pláticas, conforten las almas que son a su cargo, en la santa fe: que les inculquen más y más el amor a la religión santa que profesan", y a los fieles a economizar "con vuestra voluntaria prestación, sacrificios al Estado, y tiempo al supremo gobierno en el empeño que lo ocupa de cooperar con los demás aliados a libertar al pueblo nicaragüense, y dar seguridad a toda Centro América. Nos por nuestra parte, no cesaremos de rogar al Dios de los ejércitos guíe los pasos, y corone de triunfos á todos los valerosos aliados...» (22).

El obispo de El Salvador, por su parte, emitió una pastoral el 6 de octubre de dicho año, manifestando también su apoyo al gobierno salvadoreño en la guerra, para la cual «los eclesiásticos concurrirán con un subsidio que Nos les impusiéramos para los gastos de guerra en que el Estado está empeñado con los demás de Centro América... El clero debe ser ésta vez mucho más generoso y patriótico, porque la causa, queridos hijos, que el Gobierno sostiene, es la de la religión y de la patria" (23).

Más solemne, extensa y exhortativa es la pastoral que dedicó a su clero y fieles Francisco de Paula García Peláez, arzobispo de la Santa Iglesia Metropolitana de Guatemala, llamando a todos a la unión y pidiendo rogativas para lograr el triunfo de las fuerzas aliadas. De tan interesante documento sacaremos algunos elementos ilustrativos al tema. Comienza el arzobispo haciendo una alusión histórica del problema político de Nicaragua, lamentándose de la continuidad de las desgracias producidas por la guerra. Reflexiona que si esos acontecimientos "fuesen de un carácter puramente político, si ellos no tuvieran tan inmediata relación con nuestro modo de ser religioso y moral, nos abstendríamos de llamar hacia ellos vuestra atención" (24) pero no, porque preveía que tras la conquista militar se pretendía una irrupción del protestantismo en todo el istmo centroamericano. No es momento, dice, para generalizar el daño que algunos extranjeros puedan realizar, sin que ningún género de prevención contra ellos pueda cegar sus opiniones, pues entre ellos «hay muchos hombres honrados, laboriosos y buenos católicos: especialmente los que proceden de aquellas naciones en donde tan de antiguo se estableció

(22) Ciacera de Cinatemala, 19 de octubre de 1856. AMAE, Leg. 2.566.

(23) Ibidem. Todos los entrecomillados que van a continuación son de este documento.

(24) Ibidem. 
la fe y aún en nuestros dias están dando prucbas de adhesión y respeto a la Santa Iglesia». Cosa diferente es, continúa diciendo, la de aceptar la intromisión de aquellos extranjeros que pretenden establecerse en los territorios por la fuerza, un "atentado que pasa a ser una iniquidad, cuando por consumar más facilmente la usurpación se derrama la sangre de los ciudadanos, se les obliga a abandonar sus hogares y se les arrebatan sus bienes". Para el arzobispo, el mayor peligro a enfrentar era la pérdida de la libertad ciudadana y el cambio de religión, por tal razón: "todos los centroamericanos y aún los naturales de todas las naciones que antiguamente estuvieron sometidas al cetro de Castilla, deben ver en esos sucesos una formidable amenaza contra sus más caros intereses y especialmente contra su religion, porque en los pliegues de la bandera invasora, vendrá sin duda oculto el error religioson.

Los llamados del prelado son para que todo el pueblo cristiano apoye las acciones libertadoras de los gobiernos, y que un objeto especial de las oraciones conjuntas debe ser «la suerte de nuestros soldados. Ellos van en el nombre de Dios y con la bendición que Nos, indigno ministro suyo, les damos con toda la efusión de nuestro corazón, á defender la fe de nuestros mayores, la independencia y el honor de nuestro pais".

Dos son las formas coincidentes en que las autoridades eclesiásticas centroamericanas hacer ver su apoyo a la lucha armada que los gobiernos aliados emprendieron contra Walker y su ejército: las ayudas económicas (dinero) directas, recogidas a través de limosnas dadas por los fieles, contribuciones directas del clero en general, que espontáneamente ó por mandato de los obispos se acordó dar. En algunas diócesis, como la de Honduras, se sacaron a la calle imágenes religiosas, para pedir limosna en favor del ejército aliado. La otra forma de apoyo la constituyó el mandato dado al clero de todas las diócesis de elevar plegarias y oraciones al Creador por los soldados aliados y por el pueblo nicaragüense. Así, el doctor Casiano y Flores, obispo de Honduras, en su pastoral, ordenaba a los párrocos y demás sacerdotes que agregaran, a sus oraciones de costumbre, la de "contra persecutores Ecclesiae", y que su pastoral fuera leída en el primer día festivo. Igualmente el arzobispo García Peláez ordenó que: «Se celebraran tres dias de rogativa solemne, en nuestra Santa Iglesia Catedral... con la Misa votiva Tempore belli, cantándose las letanías mayores con las preces correspondientes al tiempo de guerra; y solemnizándose este acto con la asistencia del venerable clero

\section{R. I., 1993, $\mathrm{n}^{0} 198$}


en dichos tres días» (25). Asímismo ordenaba que en todas las iglesias de Guatemala se celebrara una misa para los fines de la rogación, con el Santísimo :xpuesto; en la misma orden exponía su disposición de dar indulgencias, hasta por ochenta días, a los fieles que rezasen las letanías mayores, y por último, la orden de que su pastoral se publicara kinter missarum solemnia».

Ya hemos dicho que para la Iglesia católica la guerra contra los filibusteros era una especie de "cruzada religiosa" en defensa del catolicismo, religión dominante en la Centro América de entonces; por lo menos así lo juzgaron también los soldados de las tropas costarricenses y salvadoreñas, que llevaban como insignia una cruz de palma en sus sombreros, recordando, además, c'ıe iban a la lucha con las bendiciones de los sacerdotes.

Destacado papel tuvo la Iglesia también en el auxilio y curación de los enfermos atacados por el cólera, enemigo mortal y no esperado en tan difícil coyuntura. Hospitales religiosos, sacerdotes y religiosas, medicinas y atenciones, se pusieron pronto a la ayuda de los enfermos. Ciudades costarricenses como Liberia, Esparza, Puntarenas y Alajuela sufrieron duramente el azote de la epidemia. Un columnista del Boletín de Costa Rica, escribía, en julio de 1856, un artículo sobre la epidemia recordando la labor de un religioso diciendo: "Acudiendo a todos, con valerosísima abnegación, con infatigable constancia, con apostólica piedad, se ha visto a un joven Sacerdote que de dia y de noche, sin dormir, sin alimentarse, olvidándose de sí mismo por atender a los desgraciados que la enfermedad postraba o que Dios llamaba a la mansión del eterno descanso.... ese Sacerdote es el modesto y virtuoso joven Dn Eduardo Pereira. Ah! Nada hay más bello, nada más digno de alabanza y veneración que el Sacerdote que cumple tan dignamente su espinosa misión sobre la tierra" (26).

Al triunfo del ejército Unionista y a la alegría general que produjo la derrota de Walker, se unió la lglesia de toda Centro América, echando las campanas al vuelo en todos los templos, ofreciendo solemnes Te Deum en las catedrales, of iciándose misas y rogativas en las parroquias y ermitas, y manifestando los respetos y felicitaciones a los gobiernos triunfadores.

El fusilamiento de Walker terminó con los temores inmediatos de los eclesiásticos, que veían muy próxima la amenaza del protestantismo en sus diócesis, porque siendo aquel partidario de la libertad de cultos, en el más claro concepto, fácilmente podían

(25) Ibidem.

(26) Gaceta de El Salvador, 24 de julio de 1856. AMAE. Leg. 2.566. 
llegar a Nicaragua predicadores protestantes, como en efecto así lo hicieron mientras Walker ejerció como presidente y jefe militar. La religión católica siguió siendo la dominante en Centroamérica a lo largo de todo el siglo XIX y si bien es cierto que algunas ideas protestantes, publicadas en libros, periódicos y folletos, llegaron a circular, éstos carecieron de un número elevado de lectores y simpatizantes como para hacer de estas una nueva doctrina religiosa. La Iglesia en conjunto, se enfrentaría más tarde, a los problemas de poder y privilegio que originaron los enfrentamientos de ésta institución con los regímenes liberales. Sólo hasta el presente siglo, nuevas ideas religiosas calaron en la mentalidad de los centroamericanos. 